\title{
KAJIAN MAKNA HUNIAN PASKA BENCANA DALAM SUDUT PANDANG FILOSOFIS
}

\author{
Stephanus Evert Indrawan ${ }^{1,}$ LMF Purwanto ${ }^{2}$, Prasasto Satwiko ${ }^{3}$, Krisprantono ${ }^{4}$ \\ ${ }^{1}$ Program Studi Doktor Arsitektur Konsentrasi Arsitektur Digital Universitas Katolik Soegijapranata Semarang \\ Program Studi Arsitektur Universitas Ciputra Surabaya, email: sindrawan@ciputra.ac.id ${ }^{2,3,4}$ Program Studi Doktor \\ Arsitektur Konsentrasi Arsitektur Digital Universitas Katolik Soegijapranata Semarang
}

\begin{abstract}
Indonesia is a disaster-prone country, especially in recent years. Post-disaster houses are needed in the post-disaster period to accommodate and recover victims. Post-disaster houses are required to protect victims from aftershocks and functional purposes and act as a medium for psychological recovery for the victims. Therefore, this paper aims to map the philosophical perception that has discussed the meaning of "house." This writing utilizes the literature studies method. There are three domains in the following studies, mainly philosophy, vernacular architecture, and Nusantara architecture. In the study of philosophy, there are writings by Heidegger, Bolnow, Bachelard, and Levinas.

Meanwhile, in the study of Vernacular and Archipelago Architecture, the writings of Heidegger and a combination of Maria Hidayatun, Josef Prijotomo, and Galih Widjil Pangarsa will be represented. Through this paper will conclude with the meaning of dwelling. House is about the human relationship with the universe. Housing is a physical and non-physical boundary with nature; residential elements also form humans. Humans are analogous to the human body itself. The variety of housing is a dialect in an architectural language, realizing housing is universal and comfortable in the spatial environment.
\end{abstract}

\section{Keywords: Post-disaster houses, Philosophy, Vernacular Architecture, Nusantara Architecture}

\begin{abstract}
Abstrak
Indonesia merupakan negara yang rawan bencana terutama dalam beberapa tahun terakhir ini Dalam penyelesaian kondisi paska bencana dibutuhkan rumah-rumah tanggap bencana untuk menampung dan memulihkan kondisi korban. Hunian paska bencana dibutuhkan tidak hanya semata-mata melindungi korban dari potensi bencana lanjutan dan ebutuhan fungsional semata. Hunian juga diharapkan berfungsi sebagai media untuk pemulihan psikis para korban terdampak. Oleh sebab itu penulisan ini bertujuan untuk memetakan persepsi akan hunian dari sudut pandang filosofi yang pernah membahas makna hunian dalam tulisan mereka. Metode yang diterapkan dalam penulisan adalah studi Pustaka. Adapun Pustaka yang menjadi bahan kajian terbagi dalam 3 bagian yakni filsafat, arsitektur vernakular dan arsitektur nusantara. Dalam kajian filsafat tulisan akan diwakili oleh Heidegger, Bolnow, Bachelard dan Levinas. Sedangkan dalam kajian Arsitektur Vernakular dan Nusantara akan diwakili oleh tulisan Heidegger dan gabungan tulisan dari Maria Hidayatun, Josef Prijotomo dan Galih Widjil Pangarsa. Melalui tulisan ini dapat ditarik enam kesimpulan akan makna hunian. Hunian merupakan relasi manusia dengan semesta, hunian merupakan batasan fisik dan non fisik dengan alam, elemen hunian turut membentuk psikis manusia, hunian dianalogikan sebagai tubuh manusia itu sendiri, ragam

hunian merupakan dialek dalam susunan bahasa arsitektur, perwujudan hunian merupakan kesemestaan dan kesamaan dalam merespon lingkungan spasial.
\end{abstract}

Kata-kunci : hunian paska bencana, filsafat, arsitektur vernakular, arsitektur nusantara 
Jurnal Arsitektur ALUR - Vol 4 No 2 September 2021

e-ISSN 2685-1490; p-ISSN 2615-1472

\section{Pendahuluan}

Indonesia merupakan negara yang rawan bencana terutama dalam beberapa tahun terakhir ini Dalam penyelesaian kondisi paska bencana dibutuhkan rumah-rumah tanggap bencana untuk menampung dan memulihkan kondisi korban. Hunian paska bencana dibutuhkan tidak hanya sematamata melindungi korban dari potensi bencana lanjutan dan ebutuhan fungsional semata. Hunian juga diharapkan berfungsi sebagai media untuk pemulihan psikis para korban terdampak. Proses rehabilitasi dalam menyelesaikan kondisi ini membutuhkan waktu maupun tenaga yang cukup besar melalui kerjasama beberapa pihak. Oleh sebab itu untuk proses rehabilitasi ini dibagi dalam 3 tahapan pertama Emergency Shelter merupakan hunian darurat yang dibangun melalui kerjasama berbagai pihak setelah kejadian dan merupakan tanggapan atas kebutuhan warga terdampak. Pemerintah setempat, organisasi dan kelompok masyarakat turut membantu untuk mendistribusikan perlengkapan dan fasilitas perlindungan darurat. Jenis hunian ini sifatnya darurat dan dalam jangka waktu yang singkat. Produk shelter ini tidak menyediakan fasilitas tempat tinggal yang memadai untuk memenuhi kebutuhan hunian selama dua sampai tiga tahun pertama atau pada masa rekonstruksi awal. , kedua Transitional Shelter, hunian ini bertujuan untuk menjawab kekurangan pada langkah awal yang telah dikerjakan dan merupakan solusi untuk rentang waktu yang lebih panjang dalam mempersiapkan hunian yang permanen. Hunian transisi juga terintegrasi dalam sektor penting lainnya seperti fasilitas penyediaan air, fasilitas ekonomi dan sosial sehingga dapat diterapkan pada kawasan terdampak dalam skala yang luas. Produk shelter transitional bukanlah solusi untuk tempat tinggal ideal dan permanen, solusi ini ditujukan untuk memperbaiki kualitas kesehatan warga terdampak dan membantu proses pemulihan komunitas. Pendekatan ini juga dipopulerkan oleh Corsellis dan Vitale (2005) berdasarkan beberapa pengalaman dalam menyediakan tempat berteduh selama keadaan darurat kompleks yang melibatkan situasi pascabencana dan paska konflik dan ketiga Permanent Shelter adalah hunian yang bertujuan untuk merehabilitasi korban ke lingkungan permanen yang lebih layak dengan memperhitungkan lebih banyak faktor, sehingga korban dapat kembali beraktivitas dalam lingkungan baru mereka (Gajah Mada University n.d.).

\section{Latar belakang Masalah dan Tujuan}

Hunian paska bencana dibutuhkan tidak hanya semata-mata melindungi korban dari potensi bencana lanjutan dan kebutuhan fungsional semata. Hunian juga diharapkan berfungsi sebagai media untuk pemulihan psikis para korban terdampak. Dari sekian banyak solusi paska yang pernah diterapkan tidak ada satupun solusi yang dianggap sukses karena setiap solusi bersifat individual terhadap kondisi bencana setempat(Architecture for Humanity (Organization) 2006). Oleh sebab itu penulisan ini bertujuan untuk memetakan persepsi akan hunian dari sudut pandang filosofis yang pernah membahas makna hunian dalam tulisan mereka.

\section{Metode}

Dalam tulisan ini metode yang digunakan adalah studi pustaka. Menurut Mardalis studi Pustaka adalah kegiatan mengumpulkan dokumen, buku, media cetak maupun segenap dokumen sejarah terkait (Mardalis 1995). Studi Pustaka juga dapat diartikan sebagai teknik mengumpulkan data melalui penelaahan buku rujukan, literatur, jurnal serta berabagai laporan yang memiliki keterkaitan dengan masalah yang ingin diselesaikan(Nazir 1985). Menurut Sugiyono, studi pustaka merupakan kajian teoritis, refrensi terkait dan literatur ilmiah yang berhubungan dengan budaya, nilai maupun norma yang ada dalam lingkungan sosial obyek penelitian (Sugiyono 2015). Langkah-langkah penelitian yang dilakukan adalah menentukan topik, eksplorasi dan ekstrak informasi, menentukan fokus penelitian, mengumpulkan data dari berbagai sumber, menyajikan data dan menyusun kesimpulan. Instrumen dari pengumpulan data adalah dengan mencari segenap informasi mengenai hal maupun variabel dari berbagai jurnal, literatur, makalah dan lain sebagainya (Arikunto 1992).

\section{Metafora}

Dalam tulisan ini dilakukan kajian makna hunian dengan pendekatan metafora. Menurut Aristoteles metafora adalah penerapan nama yang dimiliki sebuah hal atau obyek ke sesuatu yang berbeda, pemindahan dari genus ke species, species ke species secara proporsional. Pada intinya metafora merupakan pemahaman suatu jenis hal dalam konsep yang berbeda (Lawler, Lakoff, and Johnson 1983) Metafora dapat sebagai media untuk memahami pemahaman parsial maupun fenomena yang 
kompleks (Ricoeur 1975). Metafora memberikan gambaran konseptul dari hal maupun situasi yang sulit disampaikan secara tepat dan rasional tidak terbatas dalam penggunaan bahasa sehari-hari namun juga sudah meresap kedalam tindakan dalam aktivitas sehari-hari. Pemahaman makna yang menjadi pengalaman sehari-hari "Rumah" adalah contoh yang sangat baik dari hubungan intrinsik antara bahasa ini dan pengalaman sehari-hari. Di satu sisi, "rumah" sering digunakan dalam metafora cara untuk mengungkapkan pengalaman yang sulit diungkapkan dengan kata lain. Di sisi lain, dalam deskripsi pengalaman "rumah", orang cenderung menggunakan metafora awalnya berasal dari konteks lain. Dalam sebuah karya sastra metafora seringkali menggambarkan pengalaman seseorang yang terkait dengan isu lingkungan spasial, memori, identitas diri(. Seseorang yang berada didalam rumahnya dapat berinteraksi dengan baik terhadap lingkungan spasialnya karena tubuh manusia (sebagai subyek) mengenali ruangan tersebut (Krasner 2005). "Rumah" adalah contoh yang sangat baik dari hubungan intrinsik antara bahasa ini dan pengalaman sehari-hari. Di satu sisi, "rumah" sering digunakan dalam metafora cara untuk mengungkapkan pengalaman yang sulit diungkapkan dengan kata lain. Di sisi lain, dalam deskripsi pengalaman "rumah", orang cenderung menggunakan metafora awalnya berasal dari konteks lain. Dalam karya sastra seseorang dapat menemukan metafora yang menggambarkan pengalaman berada di rumah, terutama dalam kaitannya dengan jalinan isu-isu seperti lingkungan, memori, diri, dan identitas (Krasner 2005). Sebuah metafora yang sering digunakan untuk menjelaskan bagaimana lingkungan yang mendukung identitas adalah "gerakan mudah melalui lanskap" (Krasner 2005). Seseorang yang berada di rumah " dapat bergerak dengan lancar melalui tempat tinggal karena tubuh-subjek mengetahui ruang itu secara dekat" (Krasner 2005). Rumah menjadi perwujudan diri sebuah individu.

\section{Kajian Filosofis dalam sudut pandang filsafat}

Pada bagian ini akan dibahas kajian filofis dalam sudut pandang Heidegger, Bollnow, Bachelard dan Levinas. Mereka banyak sekali menulis mengenai fenomenologi rumah atau hunian sebagai tema sentral dalam konteks filosofi. Menurut Dekker(Dekkers 2009) tulisan mereka ini memaknai proses membangun rumah atau hunian (dalam konteks non fisik) dan proses menghuni rumah merupakan esensi dasar dalam eksistensi manusia. Untuk mempertegas pemahaman arsitektural maka kajian dilanjutkan dengan kajian filosofis dari sudut pandang Arsitektur Vernakular Adapun tulisan yang digunakan sebagai refrensi adalah :

Tabel 1. Daftar Kajian Sumber : Penulis

\begin{tabular}{ccccc}
\hline No & Nama Penulis & Judul Literatur & Tahun terbitan & Ranah Kajian \\
\hline 1 & Heidegger & $\begin{array}{c}\text { Building Dwelling } \\
\text { Thinking (Bauen } \\
\text { Wohnen Denken) }\end{array}$ & 1954 & Filosofis \\
\hline 2 & Bollnow & $\begin{array}{c}\text { Lived-Space (Der } \\
\text { erlebte Raum) }\end{array}$ & 1960 & Filosofis \\
\hline 3 & Bachelard & $\begin{array}{c}\text { The Poetics of } \\
\text { Space (La poe 'tique } \\
\text { de l'espace) }\end{array}$ & 1957 & Filosofis \\
\hline 4 & Amos Rapoport & $\begin{array}{c}\text { House Form and } \\
\text { Culture }\end{array}$ & 1961 & Arsitektur \\
& GW Pangarsa Maria I & Merah Putih & Arsitektur \\
& Hidayatun, Joseph Prijotomo & $\begin{array}{c}\text { Arsitektur Nusantara } \\
\text { dan Jurnal akademik }\end{array}$ & 2006 & Nusantara \\
\hline
\end{tabular}

\section{Martin Heidegger : Geviert atau Fourfold atau Empat elemen hunian}

Dalam bukunya Building Dwelling Thinking dijelaskan secara gamblang mengenai eksistensi kehidupan manusia. Heidegger menyebutkan bahwa sebagai manusia biasa yang tidak abadi, esensi kehidupan adalah untuk menghuni bumi ini (Heidegger and Hofstadter 1971). Dalam tulisannya Heidegger pada esay Bauen Wohnen Denken, mempertanyakan apakah artinya hunian dan menghuni. Pada umumnya manusia berpikir bahwa untuk menghuni sebuah tempat diawali dengan proses membangun dalam makna konstruksi bangunan, sehingga hunian dimaknai sebagai tujuan akhir dari 
proses pembangunan dan semata-mata untuk penyediaan sarana-prasarana. Proses inilah yang disoroti oleh Heidegger, menurutnya proses konstruksi adalah sebagai jembatan untuk mencapai hunian fisik namun menghunian merupakan sebuah cara manusia untuk hidup didalam bumi ini. Dalam kutipan dalam bukunya Heidegger menegaskan "Kami tidak tinggal karena kami telah membangun, tetapi tujuan kami membangun karena ingin bertempat tinggal didalamnya karena kami merupakan penghuni". Kalimat ini secara antropologis mendeskripsikan karakter manusia dalam beradaptasi di lingkungan yang baru yakni belajar untuk menghuni. Menghuni tidak hanya terkait dengan fisik rumah, Heidegger mengilustrasikan seperti supir truk dan beberapa profesi lainnya yang merasa betah (being at home) dalam lingkungan kerja mereka, namun mereka tidak bermukim atau bertempat tinggal disana. Sehingga definisi being at home atau betah memiliki makna yang lemah jika dikaitkan dengan keberadaan manusia dalam konteks waktu atau konteks Sein und Zeit (Rentsch 2003). Dalam konsep Geviert atau Fourfold terdapat 4 elemen yang dapat menggambarkan esensi tempat tinggal (hunian) manusia di bumi ini yakni bumi, langit, Yang Mahakuasa dan relasi antar manusia. Walaupun Heidegger tidak secara eksplisit menghubungkan konsep ini terhadap hunian namun Wim Dekker mencoba menjelaskan keterkaitan bumi dan langit merupakan wadah eksistensi seluruh umat manusia yang berada dibawah Yang Mahakuasa dimana keberadaan ini disatukan dalam sebuah relasi yang erat antar mahkluk-mahkluk yang tinggal didalamnya. Atau dari segi arsitektur secara pragmatis dapat dimaknai bahwa nilai keberlanjutan terkait dengan konsep bumi-angit, nilai kepercayaan maupun tradisi terkait dengan Yang Mahakuasa dan nilai sosial budaya terkait dengan relasi antar umat manusia, kaitan keseluruhan konsep ini akan membentuk sebuah hunian yang asri dan harmoni.

\section{Bollnow : Lived-Space (Ruang hunian)}

Tulisan Bollnow ini terinsipirasi dari sebuah buku yang berjudul Lived Time (Le Temps vécu, 1933) sehingga memunculkan judul Living Space atau Erlebter Raum (Bollnow 1961). Sejak saat tulisan ini menjadi populer maka istilah living space semakin sering digunakan dalam konteks akademis. Dalam buku ini Bollnow menyampaikan kritiknya terhadap filsafat eksistensi diri manusia yang berpusat pada diri sendiri dan mengabaikan relasi dengan lingkungan sekitar. Menurut dia dibutuhkan refleksi yang komprehensif mengenai ruang hidup (erlebter raum) dengan prasangka awal sekecil (Tweed 2000). Bollnow meninjau makna hunian melalui hal mendasar yakni rumah atau hunian merupakan konsep dasar kehidupan manusia dan membaginya dalam 3 hal yakni pertama hunian sifatnya berakar pada tempat dimana individu berada dengan dibatasi tembok yang kokoh sehingga individu yang hidup didalamnya memiliki eksistensi yang kuat dan tidak terbawa arus waktu. Kedua hunian membatasi ruang dalam dan luar. Ada 3 konsep besar untuk ruang luar yakni 1. dunia luar sangatlah luas sedangkan rumah sempit dan terbatas 2. Dunia luar penuh dengan keanehan dan ketidakpastian namun ruang dalam penuh dengan kepastian dan pengetahuan dan 3. Dunia luar terbuka dan berpotensi berbahaya namun ruang dalam sebagai tempat berlindung bagi manusia. Ketiga Batasan ruang dalam dan luar samar samar. Walaupun manusia membutuhkan tempat berlindung maupun bersembunyi namun manusia jga masih membutuhkan dunia luar untuk memenuhi kebutuhan sehariharinya. Sehingga pendapat Bollnow tentang hunian dapat disimpulkan bahwa hunian adalah sebuah tempat yang permanen atau ditinggali dalam jangka waktu yang panjang dimana ruang didalamnya dapat digunakan sebagai tempat berlindung namun tidak bersifat mengurung atau mengucilkan manusia dari dunia luar.

\section{Gaston Bachelard : reading houses}

Rumah merupakan gambaran diri dari pemiliknya dan setiap ruangan maupun komponen pembentuknya merupakan bagian dari diri manusia(Bachelard 2017). Bachelard memiliki konsep pendekatan mengenai hunian dan semesta yang hampir sama dengan Geviert yakni bumi, langit, Yang Mahakuasa dan relasi manusia. Namun Bachelard memiliki konsep yang dilatar belakangi oleh mitos Yunani yakni tanah, air, udara dan api. Seperti yang telah dia tuangkan dalam bukunya The psychoanalysis of fire, Water and Dreams, Air and revery dan The earth and reveries of the will. Bachelard memiliki ketertarikan pada aspek material yang mempengaruhi kehidupan manusia, oleh sebab itu tulisannya membahas rumah, kamar, Gudang, sudut ruangan, laci, lemari dan seterusnya. Bachelard melihat sebuah hunian terbentuk melalui komponen-komponen ruang penyusunnya dan membagi definisi "home" dalam makna psikologis dan "house" dalam makna fisik. Selanjutnya Bachelard membedakan ruang-ruang dengan fungsi spesifik didalam rumah seperti kamar tidur, ruang makan, dapur dengan ruang yang tidak memiliki fungsi spesifik seperti gudang, selasar, lorong dan memaknainya seperti bagian yang dipenuhi dengan kesadaran manusia (consiussness) dan tidak sadar (unconsciousness). 


\section{Levinas : as the condition of life}

Menurut Levinas rumah tidak hanya sebagai alat untuk melindungi manusia dari kondisi iklim atau tempat berteduh manusia dari gangguan alam. Dalam kehidupan manusia yang demikian kompleks, hunian bukanlah sebagai "tujuan" awal maupun akhir dalam kehidupan manusia namun menjadi sebuah "situasi". Menurut Levina hunian sebagai media eksistensi manusia memiliki posisi yang sama seperti konsep "kesadaran berpikir" dalam filosofi Descartes, namun Levina tidak sependapat dengan dikotomi Cartesian yang berpendapat bahwa pengetahuan ilmiah dapat diturunkan secara apriori melalui penalaran yang bersifat deduktif. Levina juga menambahkan bahwa hunian tidaklah terbatas hanya dalam makna arsitektural semata dan hunian juga bisa dimaknai sebagai ruang utopia (juga non utopia) karena Levina berpendapat yang menjadi peran utama eksistensi hunian adalah manusia itu sendiri(Lévinas 1969).

\section{Kajian Filosofis dalam sudut pandang Arsitektur}

\section{Vernakular Amos Rapoport, House Form and Culture}

Pada tahun 1969 Amos Rapoport pernah menyebutkan bahwa arsitektur vernakular dikembangkan mealui tradisi berarsitektur masyarakat awam yang dipengaruhi dan didukung oleh segenap informasi terkait tradisi(Lozar and Rapoport 1970). Pendekatan ini berpotensi mengangkat nilai terkait elemen pembentuk bangunan seperti material, teknologi dan pengetahuan itu sendiri. Dalam buku Dwellings : The House Across The World yang ditulis oleh Paul Oliver disebutkan bahwa arsitektur vernacular adalah sebuah pemahaman arsitektur yang "biasa" atau "plain". Namun yang dimaksud dengan hal tersebut adalah bahwa pemikiran sederhana terhadap tuntutan arsitektur yakni ekonomis, dibangun oleh komunitas tradisional yang mempertahankan budaya lokalnya. Walaupun demikian perkembangan pemahaman arsitektur vernakular juga dapat dilihat sebagai perkembangan pengetahuan ekologi, pemahaman tektonika dan relasi sosial budaya. Menurut Rapoport sebuah bentukan hunian bukan hanya terjadi karena faktor fisik pembentuknya melainkan konsekuensi dari berbagai faktor sosial budaya yang ada dan dalam makna yang tidak sempit. Penelusuran Rapoport berbeda jika dibandingkan dengan pola penelusuran sejarah arsitektur dunia. Sejarah arsitektur dunia melakukan penelusuran melalui bangunan yang dikategorikan sebagai monument dan "high style" dalam berbagai perkembangan peradaban. Tulisan Rapoport berdasarkan karakteristik bangunan primitive-vernakular dan bangunan modern disisi yang berbeda. Hal ini dilakukan karena menurut Rapoport bahwa bangunan primitif dihasilkan oleh masyarakat primitif yang memiliki pengetahuan dan pemahaman teknologi yang paling mendasar.

\section{Arsitektur Nusantara - Regionalisme , kesamaan dan kesemestaan}

Arsitektur Nusantara merupakan wujud asitektur yang merefleksikan eksistensi manusia, alam lingkungannya dan relasi kepada Yang Maha Pencipta dalam sebuah kesatuan yang utuh. Dalam penjelasan Pangarsa disebutkan bahwa Arsitektur Nusantara perlu dipandang dalam sudut Nusantara itu sendiri. Nusantara yang penuh dengan segala keragamanan 726 bahasa suku, diatas permukaan tanah masa kini, dimana didalam keberagaman itu terdapat kesamaan cirinya(Pangarsa 2006). Sehingga melalui pemahaman tersebut dalam terlihat bahwa umat manusia tidak dapat hidup sebagai individu tunggal, manusia hidup dengan menjalin hubungan dengan lingkungan, relasi sosial dan dengan Yang Maha Pencipta. Setiap propinsi dan region di Indonesia memiliki keunikannya sendiri, antara lain dari pemanfaatan material, metode struktur, sistem konstruksi bahkan detail dalam setiap sudut bangunan yang mencerminkan pengetahuan terhadap teknologi maupun makna dari ekspresi bangunan itu sendiri. Keunikan inilah yang membentuk arsitektur Nusantara. Dibalik ragam keunikan terdapat kesamaan pengetahuan dalam menghadapi kondisi iklim tropis lembab dan kondisi lingkungan sekitar. Cara menghadapi kondisi iklim ini merupakan sebuah usaha manusia untuk membangun keharmonisan dengan alam atau semesta. Nilai kesamaan inilah yang dimaknai sebagai kesemestaan dalam Arsitektur Nusantara (Hidayatun, Prijotomo, and Rachmawati 2014). Kesemestaan ini dimaknai sebagai nilai universal yang merupakan bagian dari Arsitektur Nusantara. Curtis menulis bahwa dalam regionalisme arsitektur dibutuhkan adanya relasi yang erat antara nilai lokal dan nilai-nilai universal(Curtis 1996). Oleh sebab itu kesamaan dan kesemestaan inilah yang menjadi pertimbangan utama dalam Arsitektur Nusantara(Hidayatun, Prijotomo, and Rachmawati 2014). 
Jurnal Arsitektur ALUR - Vol 4 No 2 September 2021

e-ISSN 2685-1490; p-ISSN 2615-1472

\section{Pembahasan}

Dalam uraian sebelumnya telah dijelaskan tentang definisi hunian dari sudut pandang filsafati dari hal yang umum menuju ke pemahaman yang semakin spesifik. Heidegger telah menguraikan 4 faktor pembentuk hunian dalam sudut pandang relasi bumi, langit, Yang Maha Kuasa dan relasi manusia. Melalui penjelasan ini dapat dilihat bahwa lingkungan, tradisi dan sosial sangat membentuk definisi manusia akan hunian yang mendasar. Dilanjutkan penjelasan Bollnow yang menjelaskan batasbatas fisik maupun non fisik dari sebuah hunian, batas-batas inilah yang memberikan rasa aman dan nyaman dari manusia. Bachelard menjelaskan bahwa sebuah hunian tersusun dari komponenkomponen ruang sehingga menjadi sebuah hunian yang utuh. Komponen ruang ini juga dimaknai sebagai ruang-ruang kesadaran (consciousness) dan ketidaksadaran (unconsciousness) yang membentuk psikologi manusia. Diakhiri dengan penjelasan Levinas yang menuturkan bahwa hunian itu adalah individu manusia itu sendiri yang dapat dimaknai bahwa proses menciptakan hunian tidak hanya berhenti pada penyelesaian fisik bangunan semata namun sebuah hunian berkembang berdasarkan perkembangan manusia itu sendiri. Melalui penjelasan ini dapat terlihat bahwa proses perencanaan hunian paska bencana perlu mempertimbangkan faktor psikologis calon penghuninya apalagi hunian juga menjadi bagian proses pemulihan psikis. Selanjutnya pembahasan hunian melalui tinjauan arsitektur vernakular menegaskan bahwa perkembangan arsitektur hunian sangat dipengaruhi oleh perkembangan peradaban manusia baik itu berupa tradisi turun temurun maupun perkembangan teknologi. Dalam pembahasan Arsitektur Nusantara disampaikan konsep kesamaan dan kesemestaan yang dapat diartikan sebagai usaha manusia nusantara untuk merespon kondisi regionalnya masingmasing seperti kondisi iklim maupun sosial budaya dan kesemestaan adalah menyelesaikan permasalahan arsitektural yang juga melibatkan nilai-nilai universal didalamnya. Melalui pemahaman ini maka penerapan dalam penelitian kedepan akan dibagi dalam 2 kategori utama yakni hunian dalam tinjauan fisik dan non-fisik. Yang dimaksud fisik adalah terkait dengan perkembangan fisik dan teknologi konstruksi fisik yang mempengaruhinya dan non fisik terkait dengan nilai sosial budaya maupun psikologi ruang.

\begin{tabular}{|c|c|c|c|c|c|c|}
\hline Filsuf & $\begin{array}{c}\text { Martin } \\
\text { Heidegger }\end{array}$ & Bollnow & Gaston Bachelard & Levinas & Amos Rapoport & $\begin{array}{c}\text { Maria I } \\
\text { Hidayatun, } \\
\text { Joseph } \\
\text { Prijotomo, } \\
\text { GW } \\
\text { Pangarsa }\end{array}$ \\
\hline Buku & $\begin{array}{c}\text { Geviert atau } \\
\text { Fourfold }\end{array}$ & Lived-Space & reading houses & $\begin{array}{c}\text { as the } \\
\text { condition of } \\
\text { life }\end{array}$ & $\begin{array}{l}\text { House Form } \\
\text { and Culture }\end{array}$ & $\begin{array}{c}\text { Jurnal terkait } \\
\text { Arsitektur } \\
\text { Nusantara } \\
\text { dan Merah } \\
\text { Putih } \\
\text { Arsitektur } \\
\text { Nusantara }\end{array}$ \\
\hline Konsep & $\begin{array}{c}\text { relasi bumi, } \\
\text { langit, Yang } \\
\text { Maha Kuasa } \\
\text { dan relasi } \\
\text { manusia }\end{array}$ & $\begin{array}{l}\text { batas fisik } \\
\text { maupun non } \\
\text { fisik }\end{array}$ & $\begin{array}{c}\text { kesadaran } \\
\text { (consciousness) dan } \\
\text { ketidaksadaran } \\
\text { (unconsciousness) yang } \\
\text { membentuk psikologi } \\
\text { manusia }\end{array}$ & $\begin{array}{l}\text { individu } \\
\text { manusia }\end{array}$ & dialek & $\begin{array}{c}\text { Kesamaan } \\
\text { dan } \\
\text { Kesemestaan }\end{array}$ \\
\hline $\begin{array}{c}\text { Rumah } \\
\text { Paska } \\
\text { Bencana }\end{array}$ & \multicolumn{6}{|c|}{ Fisik dan Non Fisik : teknologi bangunan dan aspek sosial budaya psikologi } \\
\hline
\end{tabular}

\section{Skema Pembahasan \\ Sumber : Penulis}


Jurnal Arsitektur ALUR - Vol 4 No 2 September 2021

e-ISSN 2685-1490; p-ISSN 2615-1472

\section{Rangkuman}

Hunian merupakan sebuah wadah yang tidak sekedar menaungi manusia dari ancaman binatang buas maupun cuaca dan memenuhi kebutuhan fungsional semata, namun hunian merupakan eksistensi diri manusia dan ruang yang memberikan rasa aman lahir batin. Terutama untuk kondisi paska bencana, hunian juga merupakan media untuk mempercepat pemulihan psikis para korban bencana alam. Melalui pemahaman filosofis hunian maka perencana dapat memetakan kebutuhan hunian yang tidak sekedar mengacu pada standar menghuni yang ada namun lebih berorientasi pada kebutuhan esensialnya, yaitu memberikan rasa aman dari gangguan lingkungan luar baik secara fisik maupun psikologis dan tentu saja dengan mempertimbangkan lingkup sosial yang ada. Melalui tulisan ini dapat ditarik enam kesimpulan akan makna hunian. Hunian merupakan relasi manusia dengan semesta, hunian merupakan batasan fisik dan non fisik dengan alam, elemen hunian turut membentuk psikis manusia, hunian dianalogikan sebagai tubuh manusia itu sendiri, ragam hunian merupakan dialek dalam susunan bahasa arsitektur, perwujudan hunian merupakan kesemestaan dan kesamaan dalam merespon lingkungan spasial.

\section{Daftar Pustaka}

Architecture for Humanity (Organization). 2006. "Design like You Give a Damn : Architectural Responses to Humanitarian Crises." : 333.

Arikunto, $\quad$ S. 1992. Prosedur Penelitian: Suatu Pendekatan Praktik. Rineka Cipta. https://books.google.co.id/books?id=aO5BAQAACAAJ.

Bachelard, Gaston. 2017. Metamorphosis of the Private Sphere The Poetics of Space: The Classic Look at How We Experience Intimate Places.

Bollnow, O. F. 1961. "Lived-Space." Philosophy Today.

Curtis, Wiliam. 1996. Regionalism in Architecture. Singapore: Concept Media.

Dekkers, Wim. 2009. "On the Notion of Home and the Goals of Palliative Care." Theoretical Medicine and Bioethics 30(5): 335-49.

Gajah Mada University. The Recovery Status Report Central Java Earthquake.

Heidegger, Martin, and Albert Hofstadter. 1971. "Building Dwelling Thinking." Poetry, Language, Thought.

Hidayatun, Maria I, Josef Prijotomo, and Murni Rachmawati. 2014. "Arsitektur Nusantara Sebagai Dasar Pembentuk Regionalisme Arsitektur Indonesia." Seminar Rumah Tradisional 2014 - Transformasi Nilai-nilai Tradisional dalam Arsitektur Masa Kini $1: 1$.

Krasner, James. 2005. "Accumulated Lives: Metaphor, Materiality, and the Homes of the Elderly."

Literature and Medicine 24(2): 209-30.

Lawler, John M., George Lakoff, and Mark Johnson. 1983. "Metaphors We Live By." Language.

Lévinas, Emmanuel. 1969. "Totality and Infinity: An Essay on Exteriority." Duquesne Studies Philosophical Series.

Lozar, Charles, and Amos Rapoport. 1970. "House Form and Culture." Journal of Aesthetic Education.

Mardalis. 1995. Metode Penelitian: Suatu Pendekatan Proposal. Bumi Aksara.

https://books.google.co.id/books?id=UtbSAAAACAAJ.

Nazir, M. 1985. Metode Penelitian. Ghalia Indonesia. https://books.google.co.id/books?id=M_-dAQAACAAJ.

Pangarsa, Galih Wijil. 2006. Merah Putih Arsitektur Nusantara. Yogyakarta: Penerbit Andi Offset.

Rentsch, Thomas. 2003. "»Sein Und Zeit«." In Heidegger-Handbuch,

Ricoeur, Paul. 1975. La Metaphore Vive / Paul Ricoeur. Paris: Seuil.

Sugiyono. 2015. "Metode Penelitian." Metode Penelitian.

Tweed, Christopher. 2000. "A Phenomenological Framework for Describing Architectural." Phenomenology and Culture (July): 1-9. http://orca.cf.ac.uk/95941/. 